Cite this: J. Mater. Chem. C, 2014, 2, 6192

Received 6th May 2014

Accepted 28th May 2014

DOI: $10.1039 / \mathrm{c} 4 \mathrm{tc00923a}$

www.rsc.org/MaterialsC

\title{
Synthesis, properties, and applications of poly(ethylene glycol)-decorated tetraphenylethenes $\uparrow$
}

\begin{abstract}
Yilong Chen, ${ }^{\mathrm{ab}}$ Jacky W. Y. Lam, ${ }^{\text {ab }}$ Sijie Chen ${ }^{\mathrm{ab}}$ and Ben Zhong Tang ${ }^{\star a b c}$
Non-charged, water soluble poly(ethylene glycol) (PEG)-decorated teraphenylethenes (TPEs) with different polymer chain numbers are synthesized in high yields by azide-alkyne cycloaddition. Their aggregation and thermosensitive behaviours are investigated by means of fluorescence spectroscopy, transmission electron microscopy (TEM), zeta potential and dynamic mechanical analyses. All the luminogens are non-emissive in solutions, but emit intensely when aggregated in aqueous solutions, or forming micelles, demonstrating a phenomenon of aggregation-induced emission. The TPE derivative (1) carrying one PEG chain forms hydrogels in the THF-water mixture depending on the concentration, water fraction and temperature. All the luminogens are thermosensitive, with their cloud point being tunable by varying the solvent composition and their hydrophilicity. Luminogen 1 is biocompatible and can function as a fluorescent visualizer for intracellular imaging.
\end{abstract}

\section{Introduction}

Since the observation of the phenomenon of aggregationinduced emission (AIE) in a series of propeller-shaped molecules, more than 100 research groups in the world are now conducting AIE research. ${ }^{1-3}$ AIE luminogens are weakly emissive or non-fluorescent in solutions but are induced to emit efficiently by aggregate formation. ${ }^{1}$ Such a characteristic enables them to find potential high-tech applications as chemosensors, bioprobes, immunoassay markers, stimuli-responsive materials and solid-state emitters. ${ }^{1-3}$ Tetraphenylethene (TPE) is a wellknown AIE luminogen and enjoys the advantages of facile synthesis, efficient quantum yield in the solid state and high chemical and photo-stabilities. However, its hydrophobic nature greatly limits its biological applications. Physical mixing with water-soluble materials such as bovine serum albumin (BSA) or surfactants help improve its solubility or dispersion in aqueous medium. ${ }^{2,3}$ Whereas this method enjoys the advantage of easy preparation, it tends to reduce the mechanical properties of the dye molecule and is difficult for quantification.

\footnotetext{
${ }^{a}$ HKUST Shenzhen Research Institute, No. 9 Yuexing 1st RD, South Area, High-tech Park, Nanshan, Shenzhen 518057, China.E-mail: tangbenz@ust.hk

${ }^{b}$ Department of Chemistry, Institute for Advanced Study, Division of Life Science, Institute of Molecular Functional Materials, Division of Biomedical Engineering and State Key Laboratory of Molecular Neuroscience, HKUST, Clear Water Bay, Kowloon, Hong Kong, China

${ }^{c}$ Guangdong Innovative Research Team, SCUT-HKUST Joint Research Laboratory, State Key Laboratory of Luminescent Materials and Devices, South China University of Technology, Guangzhou 510640, China

$\uparrow$ Electronic supplementary information (ESI) available: IR, ${ }^{1} \mathrm{H}$ NMR and ${ }^{13} \mathrm{C}$ NMR spectra of 1-3. See DOI: 10.1039/c4tc00923a
}

Chemical incorporation of positively and negatively-charged groups is found to be effective to solve this problem. For example, TPE carrying two or four ammonium groups is watersoluble and emits weakly in aqueous solution. Its fluorescence is enhanced dramatically upon binding with calf thymus DNA or bovine serum albumin (BSA), making it to work as a fluorescence "turn-on" sensor for sensitive detection of biomolecules. ${ }^{4-6}$ Electrostatic attraction or hydrophobic interaction of the TPE derivative with DNA and BSA, respectively, restricts the intramolecular rotation of the dye molecule, which blocks the nonradiative relaxation channel and hence enhances the light emission.

The thermal properties of polymers with a lower critical solution temperature (LCST) have been investigated extensively. These polymers possess both hydrophobic and hydrophilic groups and the balance between the two determines their LCST. ${ }^{7,8}$ They are soluble or swell below the LCST in aqueous medium, but precipitate or shrink at temperature above the LCST. This property enables them to find possible applications in tissue engineering and controlled drug delivery. An example is represented by poly( $N$-isopropylacrylamide) (PNIPAM), whose temperature-induced conformational change can be sensitively followed by its functionalization with TPE. ${ }^{9}$ Besides PNIPAM, poly(ethylene glycol) ( $\mathrm{PEG}$ ) is a well-known water-soluble polymer and becomes thermosensitive when melded with hydrophobic moieties. ${ }^{10,11}$ PEG-containing amphiphilic macromolecules, on the other hand, can facilely self-assemble into micelles in aqueous solution. Biocompatible PEG-containing polymers are biomolecules approved by U.S. Food and Drug Administration, and are widely used to enhance the water solubility/dispersibility and biocompatibility of quantum dots, superparamagnetic iron 
oxide nanoparticles and drug carrying polymers for bioimaging and drug delivery. ${ }^{\mathbf{1 2 , 1 3}}$ PEG has also been reported to have nonspecific interactions with biological substances to avoid immuno response and hence enhance non-specific cellular uptake. These features thus make it useful to improve the hydrophilicity of TPE and meanwhile impart the luminogen with thermosensitivity, self-assembly property and good biocompatibility. However, such a hybrid is rarely reported. ${ }^{\mathbf{1 0}}$

In this work, we explored such a possibility and synthesized water soluble, non-charged TPE derivatives with different PEG chain numbers via azide-alkyne cycloaddition. We found that TPE carrying one PEG chain (1) formed gels in the THF- $\mathrm{H}_{2} \mathrm{O}$ mixture, depending on the concentration, water fraction and temperature. All the dye molecules form micelles above the critical micelle concentration (CMC) and are thermosensitive. Luminogen $\mathbf{1}$ is biocompatible and can selectively image the cytoplasm of living cells.

\section{Results and discussion}

\section{Synthesis and characterization}

The PEG-decorated TPEs (1-3) were synthesized according to the synthetic routes shown in Scheme 1. PEG 600 with two hydroxy end groups was mono-tosylated by $p$-toluenesulfonyl chloride to afford 5, which was further reacted with sodium azide to furnish 6. Azide-alkyne cycloaddition of 6 with ethynyl-functionalized TPEs 7-9, respectively, catalyzed by copper(I) bromide in the presence of PMDETA finally gave the desirable products 1-3 in high yields. All the compounds were characterized by standard spectroscopic methods and gave satisfactory analysis data corresponding to their molecular structures. For example, the IR spectrum of 6 shows a strong absorption band associated with the azide stretching vibration at $2107 \mathrm{~cm}^{-1}$, which disappears upon its click reaction with 7 (Fig. 1A). Similarly, the $\mathrm{C} \equiv \mathrm{C}-\mathrm{H}$ and $\mathrm{C} \equiv \mathrm{C}$ stretching vibrations of 7 occur at 3277 and $2108 \mathrm{~cm}^{-1}$, which become invisible in the spectrum of 1 . All these suggest that the PEG chain has been successfully conjugated to the TPE core.

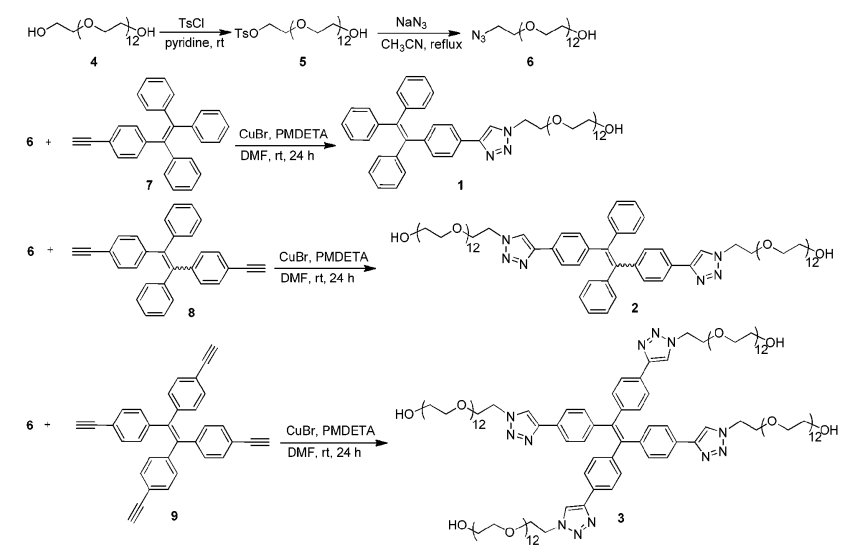

Scheme 1 Synthesis of poly(ethylene glycol)-decorated tetraphenylethenes via azide-alkyne cycloaddition.

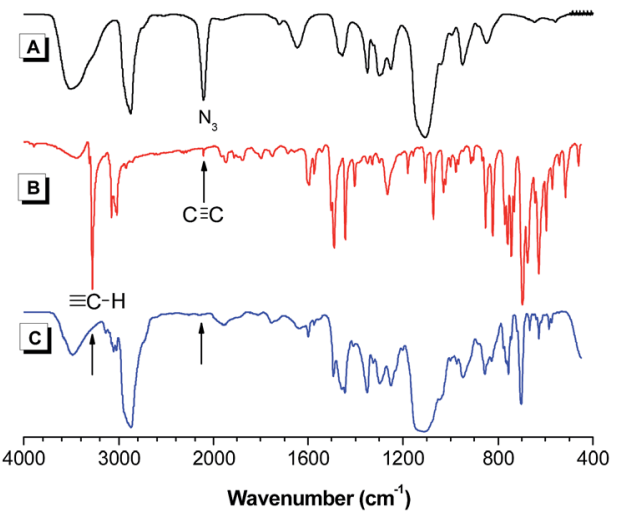

Fig. 1 IR spectra of (A) 6, (B) 7 and (C) 1 .

Similar results are obtained from the NMR analyses. The methylene protons (a) next to the azide group of $\mathbf{6}$ and acetylene proton (e) of 7 resonate at $\delta 3.28$ and 3.02, respectively, which shift to $\delta 4.59\left(\mathrm{a}^{\prime}\right)$ and $8.32\left(\mathrm{e}^{\prime}\right)$ after the click reaction due to the formation of the triazole ring in 1 (Fig. 2). On the other hand, the spectrum of 1 shows no acetylene carbon resonances of 7 at $\delta 76.8$ and 83.1 (Fig. S1 in the ESI $\dagger$ ). ${ }^{14} \mathrm{New}$ peaks emerge at the aromatic absorption region due to the cyclization of the azide group of 6 with the triple bond of 7 to form triazole rings in $\mathbf{1 .}$

\section{Aggregation and micellization}

Fig. 3A shows the UV spectra of 1-3 in THF solutions. The absorption maximum of $\mathbf{1}$ is located at $350 \mathrm{~nm}$, which is $50 \mathrm{~nm}$ red-shifted from that of unsubstituted TPE due to the electronic

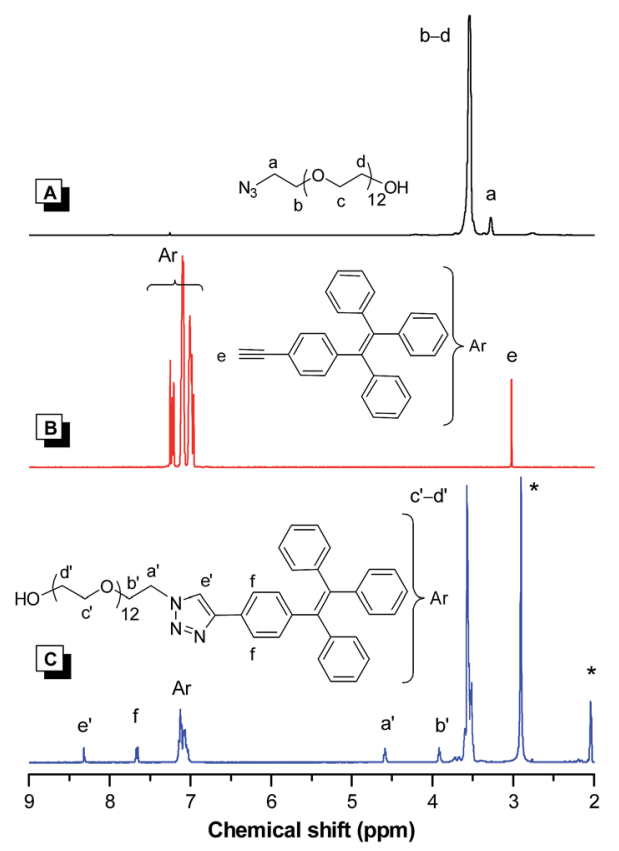

Fig. $2{ }^{1} \mathrm{H}$ NMR spectra of (A) 6 and (B) 7 in $\mathrm{CDCl}_{3}$, and (C) 1 in $\left(\mathrm{CD}_{3}\right)_{2} \mathrm{CO}$. 

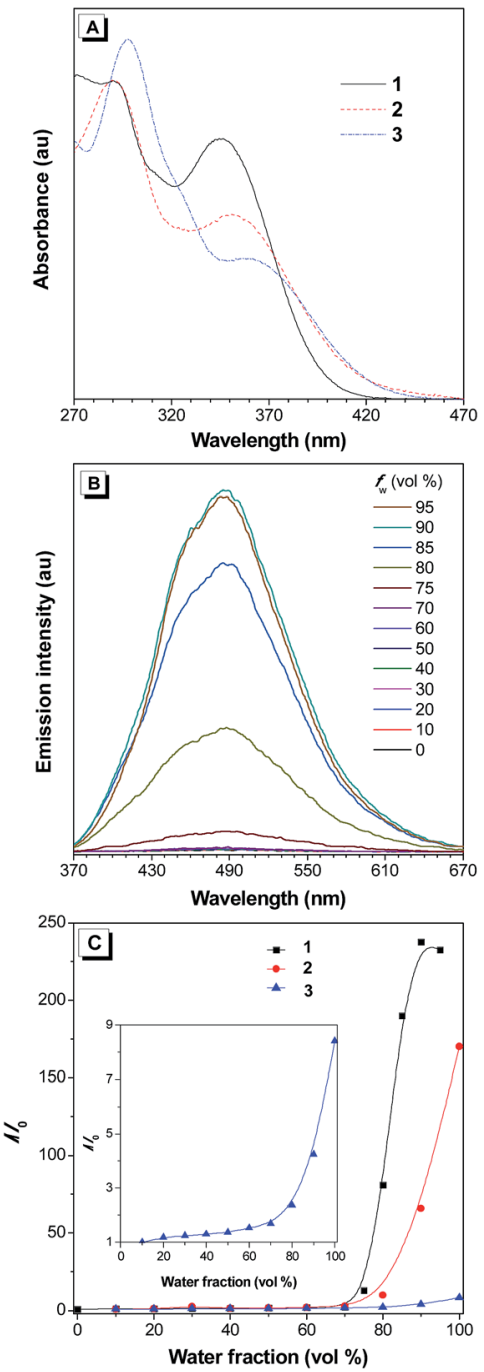

Fig. 3 (A) UV spectra of THF solutions of $1-3$. Concentration: $0.02 \mathrm{mg}$ $\mathrm{mL}^{-1}$. (B) $\mathrm{PL}$ spectra of $1 \mathrm{in} \mathrm{THF}$ and $\mathrm{THF}-\mathrm{H}_{2} \mathrm{O}$ mixtures with different water fractions $\left(f_{\mathrm{w}}\right)$. Concentration: $0.2 \mathrm{mg} \mathrm{mL}^{-1}$; excitation wavelength: $350 \mathrm{~nm}$. (C) Plot of the relative $\mathrm{PL}$ intensity $\left(/ / I_{0}\right)$ versus the composition of the $\mathrm{THF}-\mathrm{H}_{2} \mathrm{O}$ mixtures of $1-3$. Concentration (mg $\left.\mathrm{mL}^{-1}\right): 0.2$ (1) and 3 (2 and 3). Excitation wavelength: $360 \mathrm{~nm}(2)$ and $370 \mathrm{~nm}$ (3). Inset: an enlarged spectrum of 3.

communication between the TPE core and the triazole ring. Increasing the number of triazole ring connected to the TPE core further red-shifts the UV spectrum: the absorption maximum of 2 and 3 occurs at $360 \mathrm{~nm}$ and $370 \mathrm{~nm}$, respectively. The dilute THF solution of 1 emits almost no light upon photoexcitation (Fig. 3B). The emission is still weak when less than $70 \%$ of water is added into the solution. Afterwards, it rises swiftly. At $95 \%$ water content, the PL intensity is 233 -fold higher than that in pure THF solution. Since $\mathbf{1}$ possesses a hydrophobic TPE unit, its molecules should aggregate in aqueous solution with a large amount of water. Clearly, $\mathbf{1}$ inherits the property of TPE and is AIE-active. A similar phenomenon was also observed in 2 and 3 but the extent of emission enhancement upon aggregate formation is much less than that in 1 . For example, even at $100 \%$ water content or pure aqueous solution, the PL intensity of $\mathbf{2}$ and $\mathbf{3}$ increases only merely
175- and 8.5-fold, respectively. This is understandable as luminogens 2 and 3 contain more hydrophilic PEG chains and hence should possess higher solubility in aqueous solutions. Aggregates are thus less likely to be formed, thus resulting in a weak AIE effect and hence emission.

To study the micellization behaviours of the luminogens, the PL of their solutions with different concentrations was investigated at room temperature. Since the solubility of $\mathbf{1}$ in water is low, study on its micellization and gelation properties is performed in the THF-water mixture. The PL intensity of $\mathbf{1}$, for example, increases with increasing the solution concentration without causing any spectral change (Fig. 4A). The CMC can be calculated as the intersection point from the plot of relative PL intensity $\left(I / I_{0}\right)$ against the logarithm solution concentration (Fig. 4B) and is determined to be $0.1,0.4$, and $0.6 \mathrm{mg} \mathrm{mL}^{-1}$ for $\mathbf{1}$, 2 and 3, respectively. It is noticeable that the CMC value increases with the number of PEG chains, suggesting that the luminogen becomes more hydrophilic when carrying more PEG chains. Gelation was observed at a concentration of above $5 \mathrm{mg}$ $\mathrm{mL}^{-1}$ in $\mathbf{1}$, which will be discussed in the next section.

Zeta potential analysis of THF-water mixtures $(1: 9$ or $0: 10$ $\mathrm{v} / \mathrm{v}$ ) of 1-3 with a concentration of 1 or $3 \mathrm{mg} \mathrm{mL}^{-1}$ reveals particle sizes of $220.0,85.7$ and $55.6 \mathrm{~nm}$ with broad polydispersity of 0.3-0.4, respectively (Fig. 5). On the other hand, the TEM image of 1 shows spherical particles with diameters of $\sim 150 \mathrm{~nm}$ (Fig. 6). All these suggest the formation of micelles with an apolar TPE unit inside and hydrophilic PEG chains pointing to the medium. Below $\mathrm{CMC}$, the luminogens are molecularly dissolved in the medium and shows no emission. Increasing the concentration above $\mathrm{CMC}$ induces the micelle formation and aggregates the TPE core, thus making the luminogens highly emissive.

\section{Sol-gel transition and thermosensitivity}

Supramolecular gels have attracted great interest for their elegant architectures and potential high-tech applications in controlled drug release, template synthesis and biomimetics. To study the complicated gelator-gelator and gelator-solvent interactions, and the sol-gel transition process, various detection techniques such
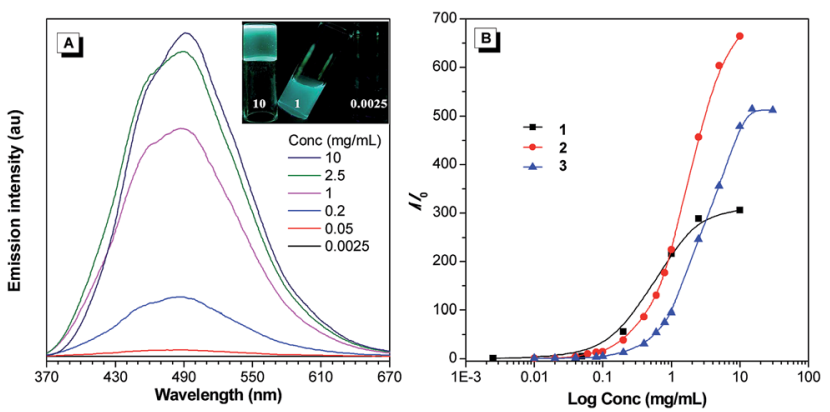

Fig. 4 (A) PL spectra of 1 in THF- $\mathrm{H}_{2} \mathrm{O}$ mixtures ( $1: 9$ by volume) with different concentrations at room temperature. Inset: photographs of $\mathrm{THF}-\mathrm{H}_{2} \mathrm{O}$ mixtures ( 1 : 9 by volume) of 1 with different concentrations taken under $365 \mathrm{~nm}$ UV irradiation. (B) Plots of relative intensity $\left(/ / /_{0}\right)$ versus the logarithm concentration of 1 in the THF $-\mathrm{H}_{2} \mathrm{O}$ mixture $(1: 9$ by volume) and 2 and 3 in water. 


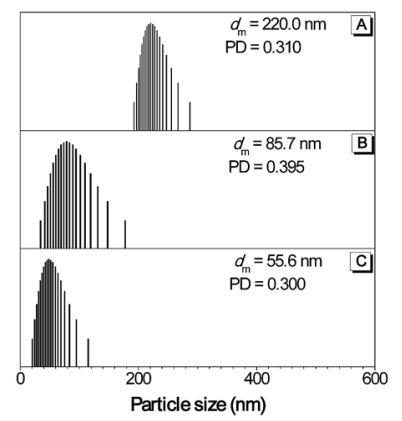

Fig. 5 Particle sizes of aggregates of (A) 1 formed in the $\mathrm{THF}-\mathrm{H}_{2} \mathrm{O}$ mixture (1:9 by volume) and (B) 2 and (C) 3 formed in water. Concentration ( $\left.\mathrm{mg} \mathrm{mL}^{-1}\right): 1$ (1) and 3 (2 and 3). Abbreviation: $\mathrm{dm}=$ mean diameter, $\mathrm{PD}=$ polydispersity.

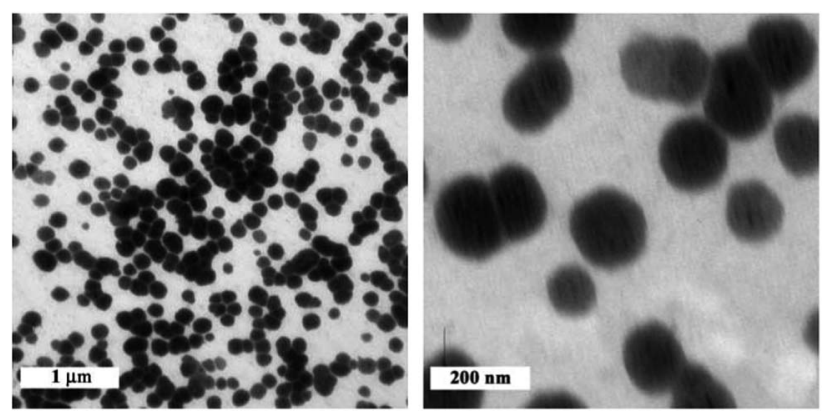

Fig. 6 TEM micrographs of 1 in the THF- $\mathrm{H}_{2} \mathrm{O}$ mixture $(1: 9 \mathrm{v} / \mathrm{v})$ at different magnifications. Concentration: $1 \mathrm{mg} \mathrm{mL}^{-1}$.

as optical observation (transmittance and dropping ball methods) and thermal analysis have been developed. These methods, however, involve the use of bulky machines and measure a general outcome of samples, losing a lot of transition details. Fluorescence-based methods, on the other hand, enjoy the advantage of high sensitivity but are rarely utilized in studying the sol-gel transition, presumably due to the aggregation-induced quenching effect observed in some conventional fluorophores. However, the efficient emission of AIE luminogens in the aggregated state makes them promising for the sol-gel transition study. Herein, we study the sol-gel transition and thermosensitivity of 1-3 using fluorescence spectroscopy.

In the previous section, we found that $\mathbf{1}$ formed gels at room temperature in the $\mathrm{THF}-\mathrm{H}_{2} \mathrm{O}$ mixture $(1: 9$ by volume) at a concentration of above $5 \mathrm{mg} \mathrm{mL} \mathrm{m}^{-1}$. This means that below this concentration, the interactions between the gelators as well as gelators and solvent molecules are too weak to form a quasisolid self-assembly system. The amount of water required for gelation can be lowered by solution thickening. As shown in Fig. 7, the PL from an aqueous solution of 1 with a concentration of $10 \mathrm{mg} \mathrm{mL}^{-1}$ is still weak when the water content is below $75 \%$. After then, the emission becomes stronger accordingly. The aqueous solution starts to emit at $70 \%$ water content when doubling the solution concentration to $20 \mathrm{mg} \mathrm{mL}^{-1}$, and a much higher PL enhancement was observed.

PEG is reported to be thermosensitive, showing LCST when attached to poly( $\varepsilon$-caprolactone). Similar behaviour was also

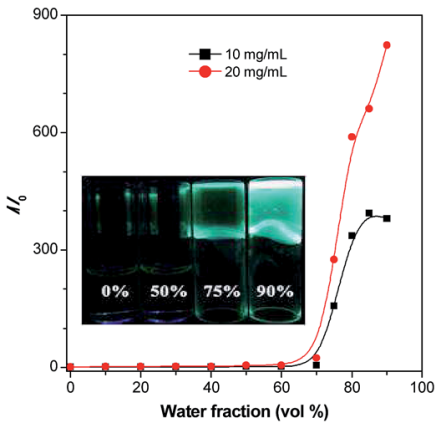

Fig. 7 Plot of relative intensity $\left(/ / I_{0}\right)$ versus the water fraction in THF$\mathrm{H}_{2} \mathrm{O}$ mixtures of 1 with concentrations of 10 and $20 \mathrm{mg} \mathrm{mL}^{-1}$. Inset: photographs of THF- $\mathrm{H}_{2} \mathrm{O}$ mixtures of $1\left(10 \mathrm{mg} \mathrm{mL}^{-1}\right)$ with different water fractions taken under $365 \mathrm{~nm}$ UV irradiation.

observed in 1-3, whose process can be followed by the temperature-dependent PL and transmittance analyses. The THF- $\mathrm{H}_{2} \mathrm{O}$ mixture $(3: 7 \mathrm{v} / \mathrm{v})$ of 1 with a concentration of $10 \mathrm{mg}$ $\mathrm{mL}^{-1}$ is transparent. Its $\mathrm{PL}$ drops progressively with increase in the solution temperature and reaches the minimum intensity at $26{ }^{\circ} \mathrm{C}$. Afterwards, the emission starts to drop again at $\sim 45{ }^{\circ} \mathrm{C}$ (Fig. 8A). Thermal agitation generally brings a dissolving effect and dehydration effect on the PL of 1-3. The dissolving effect

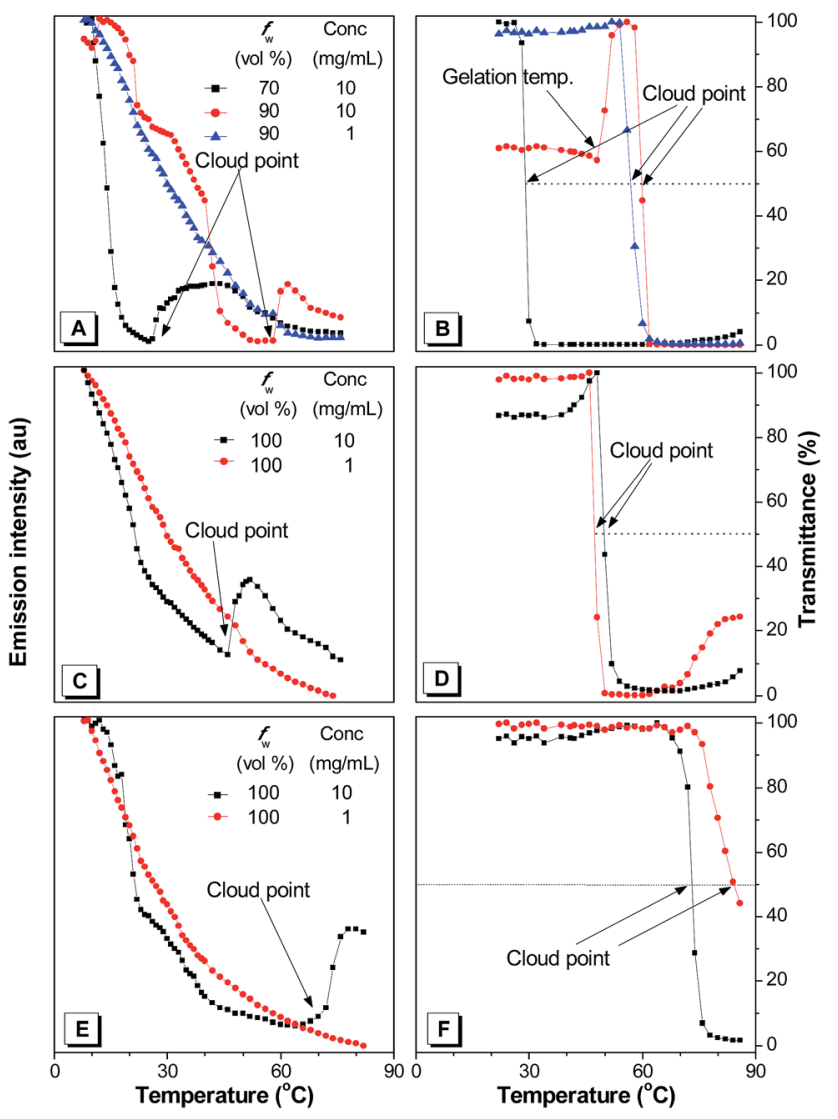

Fig. 8 Plots of ( $A, C$ and $E)$ PL intensity and ( $B, D$ and $E)$ transmittance against temperature in THF- $\mathrm{H}_{2} \mathrm{O}$ mixtures of (A and $\left.\mathrm{B}\right) \mathrm{1},(\mathrm{C}$ and $\mathrm{D}) 2$ and $(E$ and $F) 3$ with different water fractions $\left(f_{w}\right)$ and concentrations. Excitation wavelength (nm): 350 (1), 355 (2) and 360 (3). 
will enhance the molecular motion, leading to molecular separation and hence a PL drop. The dehydration effect, on the other hand, will promote molecular aggregation, resulting in PL enhancement. The first one seems to be dominated at temperature below $26^{\circ} \mathrm{C}$ or before the cloud point, while the first effect becomes more significant from 26 to $45^{\circ} \mathrm{C}$. After then, the effect of molecular motion prevails again and quenches the light emission gradually. The transmittance begins to fall at $29{ }^{\circ} \mathrm{C}$, suggesting that the PEG chain starts to dehydrate. The cloud point determined at $50 \%$ transmittance is $\sim 30{ }^{\circ} \mathrm{C}$. A similar PL change was observed in gels of $\mathbf{1}$ formed in 90\% aqueous solution with the same concentration but the cloud point now shifts to $59{ }^{\circ} \mathrm{C}$. The transmittance, on the other hand, rises at $44^{\circ} \mathrm{C}$ but drops again at $\sim 60{ }^{\circ} \mathrm{C}$. We believe that the first change is caused by gel to sol transition of the dye molecule, while the second one is caused by the dehydration of the PEG chain. The sol-gel transition is reversible and gelation occurs upon cooling the solution to lower temperatures. The PL of a less concentrated solution with the same composition, on the hand, decreases monotonically due to the predominance of the dissolving effect on the light emission process by heating even the PEG chain dehydrates and aggregates at the cloud point. The cloud point was found to be located at $57{ }^{\circ} \mathrm{C}$ from the transmittance measurement. These results show that the solvent composition exerts a stronger effect on the cloud point than the solution concentration. Similar phenomena are observed in 2 and 3. Since they are more hydrophilic than $\mathbf{1}$, their cloud points occur at higher temperatures of $49{ }^{\circ} \mathrm{C}$ and $74{ }^{\circ} \mathrm{C}$, respectively. Compared with the transmittance analysis, more information is provided by the fluorescence method. Thus, AIE fluorophores are promising in the phase transition study.

The mechanical properties of $\mathbf{1}$ are investigated by the rheometric method. As shown in Fig. 9A, the gel with an elastic modulus $\left(G^{\prime}\right)$ of $3 \mathrm{~Pa}$ and a viscous modulus $\left(G^{\prime \prime}\right)$ of $0.5 \mathrm{~Pa}$ is mechanically stable at $25^{\circ} \mathrm{C}$ and changes little with time. The $G^{\prime}$ and $G^{\prime \prime}$ increase upon heating and reach their maximum value of $40 \mathrm{~Pa}$ and $20 \mathrm{~Pa}$, respectively, at $\sim 50^{\circ} \mathrm{C}$. Afterwards, they drop dramatically due to gel to sol transition and dehydration.

As stated before, $\mathbf{1}$ forms micelles in aqueous solution at an appropriate concentration. The micelles interpenetrate into each other upon solution thickening and finally gels are
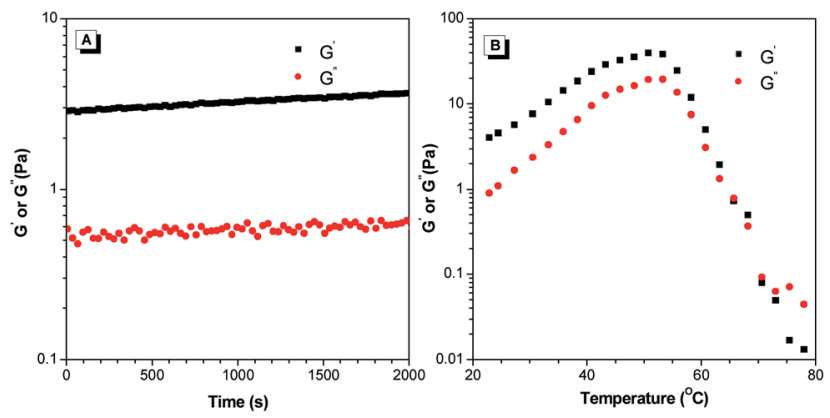

Fig. 9 Changes in the elastic modulus $\left(G^{\prime}\right)$ and viscous modulus $\left(G^{\prime \prime}\right)$ of gels of 1 formed in the THF- $\mathrm{H}_{2} \mathrm{O}$ mixture $\left(1: 9 \mathrm{v} / \mathrm{v} ; 10 \mathrm{mg} \mathrm{mL}^{-1}\right)$ with (A) time at $25^{\circ} \mathrm{C}$, a frequency of $1 \mathrm{~Hz}$ and a strain of $5 \%$ and (B) temperature at a heating rate of $5^{\circ} \mathrm{C} \mathrm{min}^{-1}$. formed. No gels are formed in $\mathbf{2}$ and $\mathbf{3}$ even at very high solution concentration, presumably due to their higher hydrophilicity as they possess a larger number of PEG chains. In order to form micelles, their PEG chains have to be bent. This gives rise to a twisted molecular conformation that may hamper gel formation. Thus, both the molecular structure and the balance between hydrophilicity and hydrophobicity of a dye molecule play important roles in its gel formation.

\section{In vitro cell imaging}

Prior to the cell imaging, the cell viability or cytotoxicity of luminogen 1 was evaluated in HeLa cells using an MTT assay. The cells were exposed to varying concentrations $(0,2.5,5,7.5,10$ $\mu \mathrm{g} \mathrm{mL}^{-1}$ ) of 1 for $24 \mathrm{~h}$ in a $\mathrm{CO}_{2}$ incubator at $37{ }^{\circ} \mathrm{C}$ for cell proliferation (Fig. 10). The result shows that luminogen 1 is generally noncytotoxic at a concentration even up to $10 \mu \mathrm{g} \mathrm{mL} L^{-1}$. The efficient PL of AIE dyes in the aggregated state makes them promising as fluorescent visualizers for intracellular imaging. However, they are normally hydrophobic and suffer low solubility in physiological medium. Some water soluble AIE dyes with charged groups have been prepared and can selectively stain the cytoplasm and mitochondrion of living cells. Non-charged water soluble AIE dyes, on the other hand, are seldom reported. Luminogen 1 is amphiphilic and possesses such capability. As shown in Fig. 11, the dye molecule stains the cytoplasmic region of HeLa Cells but not their nucleic parts. The dye molecule may also stain the mitochondria, as some bright filamentous structures are observed. Because of its amphiphilic nature, it is likely

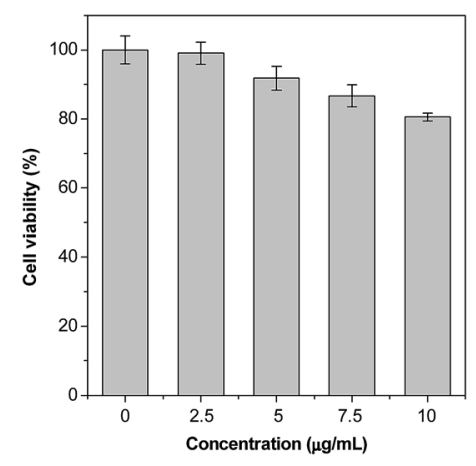

Fig. 10 Effect of 1 on cell proliferation of HeLa cells evaluated by the MTT assay. The cells were exposed to various concentrations of 1 for $24 \mathrm{~h}$.
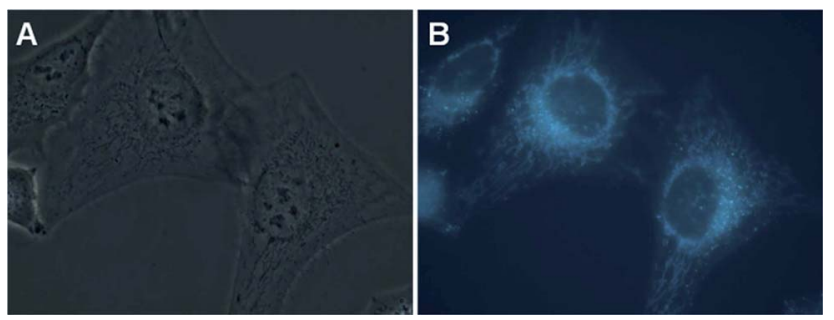

Fig. 11 (A) Bright-field and (B) fluorescent images of living HeLa cells stained with $5.2 \mu \mathrm{g} \mathrm{mL}^{-1}$ of 1 . 
that the aggregates of $\mathbf{1}$ enter other membrane-bound organelles such as the endoplasmic reticula.

\section{Conclusions}

In this work, water soluble AIE luminogens are synthesized in high yields using the technique of azide-alkyne cycloaddition. These luminogens are non-emissive in solutions but emit intensely when aggregated, displaying a novel AIE phenomenon. Under an appropriate concentration, composition and temperature, $\mathbf{1}$ forms gels in the THF-water mixture. All the luminogens are thermosensitive, with their cloud point being tunable by the solvent composition and their hydrophilicity. Luminogen 1 is cytocompatible and can function as a fluorescent visualizer for intracellular imaging.

\section{Experimental}

\section{Materials}

1-(4-Ethynylphenyl)-1,2,2-triphenylethene (7), 1,2-bis(4-ethynylphenyl)-1,2-diphenylethene (8) and 1,1,2,2-tetrakis(4-ethynylphenyl)ethene (9) were synthesized according to the literature methods. ${ }^{14}$ Poly(ethylene glycol) $\left(M_{\mathrm{n}}=600\right), p$-toluenesulfonyl chloride (TsCl), pyridine, sodium azide, copper(I) bromide, pentamethyldiethylenetriamine (PMDETA) and other chemicals and solvents were all purchased from Aldrich and used as received without further purification. Distilled water was used throughout the experiments.

\section{Instruments}

${ }^{1} \mathrm{H}$ and ${ }^{13} \mathrm{C}$ NMR spectra were measured on a Bruker ARX 400 NMR spectrometer using $\mathrm{CDCl}_{3}$ or $\left(\mathrm{CD}_{3}\right)_{2} \mathrm{CO}$ as a solvent and TMS as the internal standard. FTIR spectra were recorded on a Bruker spectrophotometer (Tensor 27). The weight-average molecular weight $\left(M_{\mathrm{w}}\right)$ and polydispersity indices (PDI or $M_{\mathrm{w}} / M_{\mathrm{n}}$ ) of the luminogens were estimated by a Waters Associates gel permeation chromatography (GPC) system equipped with RI, UV and fluorescence detectors using THF as the eluent and polystyrenes as the standard. UV-vis absorption spectra were recorded on a Cary 50 Conc UV visible spectrometer and the transmittance measurements were carried out on a UV/VIS/NIR spectrophotometer (Bruker, Lambda 900) at a wavelength of $550 \mathrm{~nm}$. Photoluminescence (PL) spectra were recorded on a Perkin-Elmer spectrofluorometer LS 55 . The temperature control was achieved by placing the sample in a cell compartment connected to the water circulation system. Water from a thermostatted bath was allowed to circulate through the walls of the sample compartment. The final temperature of the sample was measured on a digital thermometer (TES, TES-1310). The particle sizes were measured on a zeta potential analyzer (Brookhaven, ZETAPLUS). To prepare an unstained specimen for transmission electron microscopy (TEM) analysis, a drop of the sample was placed on a carbon-coated copper grid for $2 \mathrm{~min}$. The excess solution was blotted with a filter paper. After drying the grid samples in air, TEM images were taken on a TEM instrument (Japan, JEOL JEM $100 \mathrm{CXII})$ with a camera set at an accelerating voltage of $100 \mathrm{kV}$.
Rheological characterization of the gel was performed by using a Rheometric ARES 3 system with $50 \mathrm{~mm}$ parallel plate geometry. In order to avoid solvent evaporation, the surface of the sample between two plates was covered with glycerol. The evolution of moduli $\left(G^{\prime}\right.$ and $\left.G^{\prime \prime}\right)$ versus time was tested at $25{ }^{\circ} \mathrm{C}$ with a frequency of $1 \mathrm{~Hz}$ and a strain of $5 \%$. The temperature ramp was measured at $1 \mathrm{~Hz}$ frequency and a strain of $5 \%$ at a heating rate of $5{ }^{\circ} \mathrm{C} \mathrm{min}^{-1}$. For cell imaging experiment, HeLa cells were grown overnight on a plasma-treated $25 \mathrm{~mm}$ round cover slip mounted onto a $35 \mathrm{~mm}$ Petri dish with an observation window. The living cells were stained with $1\left(5.2 \mu \mathrm{g} \mathrm{mL}^{-1}\right)$ for $4 \mathrm{~h}$. The cells were imaged under an inverted fluorescence microscope (Nikon Eclipse TE2000-U) using a combination of excitation and emission filters: $\lambda_{\mathrm{ex}}=330-380 \mathrm{~nm}$. The images of the cells were captured using a computer-controlled SPOT charge-coupled device (CCD) camera (SPOT RT SE 18 Mono). HeLa cells were seeded onto a 96-well plate at a density of $8 \times 10^{3}$ per well overnight before being treated with compound 1 in different concentrations. The cell proliferation was measured using an MTT assay according to the manufacturer's instructions. After 24 $\mathrm{h}$ incubation in an incubator, the cells were washed three times with $1 \times$ PBS. After that, $10 \mu \mathrm{L}$ of 3-(4,5-dimethyl-2-thiazolyl)-2,5diphenyltetrazolium bromide (MTT) solution $\left(5 \mathrm{mg} \mathrm{mL}^{-1}\right.$ in phosphate buffer solution) was added into each well. After $4 \mathrm{~h}$ of incubation at $37^{\circ} \mathrm{C}, 100 \mu \mathrm{L}$ of solubilization solution containing $10 \%$ SDS and $0.01 \mathrm{M} \mathrm{HCl}$ was added to dissolve the purple crystals. After $8 \mathrm{~h}$ of incubation, the optical density readings at $595 \mathrm{~nm}$ were taken using a plate reader. Each of the experiments was performed at least 3 times.

\section{Synthesis of PEG 600 mono-tosylate (5)}

To a pyridine $(60 \mathrm{~mL})$ solution of $4(16.00 \mathrm{mmol})$ was added $\mathrm{TsCl}$ $(6.10 \mathrm{~g}, 32.00 \mathrm{mmol})$ and the mixture was stirred at room temperature for $2-3 \mathrm{~h}$. The reaction mixture was diluted with dichloromethane (DCM) $(200 \mathrm{~mL})$, washed with aqueous $1 \mathrm{M}$ $\mathrm{HCl}(100 \mathrm{~mL}), 4 \% \mathrm{NaHCO}_{3}$ solution and brine, and dried over anhydrous $\mathrm{Na}_{2} \mathrm{SO}_{4}$. After solvent evaporation, the residue was purified on a silica-gel column with the methanol-DCM mixture $(1: 10 \mathrm{v} / \mathrm{v})$ as the eluent. Yield $76 \%$. IR (KBr), $\nu\left(\mathrm{cm}^{-1}\right): 3436$, 2873, 1664, 1456, 1352, 1296, 1250, 1176, 1110, 923, 820, 777, 665, 554. ${ }^{1} \mathrm{H}$ NMR $\left(400 \mathrm{MHz}, \mathrm{CDCl}_{3}\right), \delta(\mathrm{ppm}): 7.79(2 \mathrm{H}, \mathrm{t}, J=8.0$ $\mathrm{Hz}, \mathrm{Ts}-\mathrm{H}), 7.34(2 \mathrm{H}, \mathrm{t}, J=8.0 \mathrm{~Hz}, \mathrm{Ts}-\mathrm{H}), 4.15(2 \mathrm{H}, \mathrm{t}, J=4.8 \mathrm{~Hz}$, $\left.\mathrm{TsOCH}_{2}\right), 3.77-3.54\left(50 \mathrm{H}, \mathrm{m}, \mathrm{OCH}_{2}\right), 2.43\left(3 \mathrm{H}, \mathrm{d}, \mathrm{Ts}-\mathrm{CH}_{3}\right)$.

\section{Synthesis of PEG 600 mono-azide (6)}

To an acetonitrile $(150 \mathrm{~mL})$ solution of $5(12.00 \mathrm{mmol})$ was added sodium azide $(1.17 \mathrm{~g}, 18.00 \mathrm{mmol})$. After reflux for $32 \mathrm{~h}$ and cooling to room temperature, the mixture was diluted with water $(200 \mathrm{~mL})$. The aqueous solution was extracted with dichloromethane four times. The combined organic phases were dried over anhydrous $\mathrm{Na}_{2} \mathrm{SO}_{4}$. After solvent evaporation, the residue was purified on a silica-gel column using methanolDCM $(1: 10 \mathrm{v} / \mathrm{v})$ as eluent. Yields $95 \%$. IR $(\mathrm{KBr}), \nu\left(\mathrm{cm}^{-1}\right): 3497$, 2873, 2107, 1644, 1455, 1350, 1293, 1251, 1108, 948, 845. ${ }^{1} \mathrm{H}$ NMR (400 MHz, $\left.\mathrm{CDCl}_{3}\right) \delta(\mathrm{ppm}): 3.77-3.44\left(50 \mathrm{H}, \mathrm{m}, \mathrm{OCH}_{2}\right), 3.28$ $\left(2 \mathrm{H}, \mathrm{t}, J=5.0 \mathrm{~Hz}, \mathrm{~N}_{3} \mathrm{CH}_{2}\right)$. 


\section{Synthesis of TPE derivatives 1-3}

Luminogen 1 was synthesized with the reagent feed ratio [6]/[7]/ [CuBr]/[PMDETA] of 1/1.1/1.1/1.1. While for 2 and 3, a feed ratio $[6] /[8] /[9]$ of $1.1 / 1 / 1$ was used instead. The click reaction between 6 (469 $\mathrm{mg}, 0.75 \mathrm{mmol}$ ) and 7 (294 mg, $0.825 \mathrm{mmol}$ ) was conducted at $35{ }^{\circ} \mathrm{C}$ in a $50 \mathrm{~mL}$ Schlenk flask with $30 \mathrm{~mL}$ of DMF, CuBr (118.4 mg, $0.825 \mathrm{mmol}$ ) and $3.65 \mathrm{~mL}$ PMDETA (0.825 $\mathrm{mmol})$. After stirring for $36 \mathrm{~h}$, the reaction mixtures were diluted with water $(300 \mathrm{~mL})$ and the aqueous solution was extracted with dichloromethane four times. The combined organic phases were further washed with brine six times and dried over $\mathrm{Na}_{2} \mathrm{SO}_{4}$. After solvent evaporation, the residue was purified on a silica-gel column using DCM as eluent to give the corresponding product in a yield of $92 \%$. For 2 and 3, the filtrates were condensed to $10 \mathrm{~mL}$ and then precipitated in ethyl ether three times. All the products were purified and characterized by GPC and FTIR, ${ }^{1} \mathrm{H}$ NMR and ${ }^{13} \mathrm{C}$ NMR spectroscopies.

Luminogen 1. Yield 92\%. $M_{\mathrm{w}} 1100 ; M_{\mathrm{w}} / M_{\mathrm{n}} 1.3$. IR (KBr), $\nu$ (cm $\left.{ }^{-1}\right): 3484,3055,2871,1950,1752,1598,1493,1446,1351$, $1298,1251,1112,1045,947,855,825,756,703,666,627,585 .{ }^{1} \mathrm{H}$ NMR (400 MHz, $\left.\left(\mathrm{CD}_{3}\right)_{2} \mathrm{CO}\right), \delta(\mathrm{ppm}): 8.32(1 \mathrm{H}, \mathrm{s}$, triazole-H), $7.66(2 \mathrm{H}, \mathrm{d}, J=7.6 \mathrm{~Hz}$, triazole-Ar-H), 7.14-7.02 (17H, m, Ar-H), $4.59\left(2 \mathrm{H}, \mathrm{t}, J=4.8 \mathrm{~Hz}, \mathrm{CH}_{2}\right.$-triazole), $3.92(2 \mathrm{H}, \mathrm{t}, J=4.8 \mathrm{~Hz}$, $\mathrm{OCH}_{2} \mathrm{CH}_{2}$-triazole), 3.60-3.51 (48H, m, $\left.\mathrm{OCH}_{2}\right) .{ }^{13} \mathrm{C}$ NMR (100 $\left.\mathrm{MHz},\left(\mathrm{CD}_{3}\right)_{2} \mathrm{CO}\right), \delta(\mathrm{ppm}): 147.42,144.62,144.02,142.13$, 141.66, 132.44, 132.03, 130.60, 128.65, 127.46, 125.59, 122.22, 73.58, 71.18, 70.12, 62.00, 50.89.

Luminogen 2. Yield 85\%. $M_{\mathrm{w}} 2100 ; M_{\mathrm{w}} / M_{\mathrm{n}}$ 1.3. IR (KBr), $\nu$ $\left(\mathrm{cm}^{-1}\right): 3418,3020,2866,2111,1645,1469,1392,1351,1300$, 1249, 1118, 971, 926, 844, 805. ${ }^{1} \mathrm{H}$ NMR (400 MHz, $\left.\left(\mathrm{CD}_{3}\right)_{2} \mathrm{CO}\right), \delta$ (ppm): $8.33(2 \mathrm{H}, \mathrm{s}$, triazole-H), $7.68(4 \mathrm{H}, \mathrm{t}, J=7.4 \mathrm{~Hz}$, triazole$\mathrm{Ar}-H)$, 7.13-7.05 (14H, m, Ar-H), $4.59\left(4 \mathrm{H}, \mathrm{t}, J=4.8 \mathrm{~Hz}, \mathrm{CH}_{2}-\right.$ triazole), 3.91 ( $4 \mathrm{H}, \mathrm{t}, J=4.8 \mathrm{~Hz}, \mathrm{OCH}_{2} \mathrm{CH}_{2}$-triazole), $3.60-3.51$ $\left(96 \mathrm{H}, \mathrm{m}, \mathrm{OCH}_{2}\right) .{ }^{13} \mathrm{C} \mathrm{NMR}\left(100 \mathrm{MHz},\left(\mathrm{CD}_{3}\right)_{2} \mathrm{CO}\right), \delta(\mathrm{ppm})$ : 147.43, 144.54, 144.09, 141.83, 132.51, 132.09, 130.09, 128.80, 127.61, 125.71, 122.38, 73.62, 71.27, 70.11, 61.97, 51.43, 50.90.

Luminogen 3. Yield 82\%. $M_{\mathrm{w}} 3600 ; M_{\mathrm{w}} / M_{\mathrm{n}}$ 1.3. IR (KBr), $\nu$ $\left(\mathrm{cm}^{-1}\right):$ 3428, 3136, 2869, 2105, 1645, 1459, 1350, 1297, 1250, 1109, 972, 946, 843, 807. ${ }^{1} \mathrm{H}$ NMR (400 MHz, $\left.\left(\mathrm{CD}_{3}\right)_{2} \mathrm{CO}\right), \delta(\mathrm{ppm})$ : $8.33(4 \mathrm{H}, \mathrm{s}$, triazole-H), $7.70(8 \mathrm{H}, \mathrm{d}, J=7.2 \mathrm{~Hz}$, triazole-Ar- $H)$, $7.17(14 \mathrm{H}, J=7.2 \mathrm{~Hz}, \mathrm{~d}, \mathrm{Ar}-\mathrm{H}), 4.57$ (8H, s, $\mathrm{CH}_{2}$-triazole), 3.89 (8H, s, $\mathrm{OCH}_{2} \mathrm{CH}_{2}$-triazole), 3.60-3.40 (192H, m, $\left.\mathrm{OCH}_{2}\right) \cdot{ }^{13} \mathrm{C}$ NMR (100 MHz, $\left.\left(\mathrm{CD}_{3}\right)_{2} \mathrm{CO}\right), \delta$ (ppm): 147.43, 144.01, 141.67, 132.67, 130.78, 125.81, 122.51, 73.61, 70.72, 70.11, 61.95, 51.43, 50.92 .

\section{Acknowledgements}

This work was partially supported by the National Basic Research Program of China (973 Program; 2013CB834701), the Research Grants Council of Hong Kong (604711, 602212, HKUST2/CRF/10, and N_HKUST620/11), the Innovation and Technology Commission (ITCPD/17-9), and the University Grants Committee of Hong Kong (AoE/P-03/08 and T23-713/111). B.Z.T. thanks the support from the Guangdong Innovative Research Team Program (201101C0105067115).

\section{Notes and references}

1 (a) J. Luo, Z. Xie, J. W. Y. Lam, L. Cheng, H. Chen, C. Qiu, H. S. Kwok, X. Zhan, Y. Liu, D. Zhu and B. Z. Tang, Chem. Commun., 2001, 1740; (b) B. Z. Tang, X. Zhan, G. Yu, P. P. S. Lee, Y. Liu and D. Zhu, J. Mater. Chem., 2001, 11, 2974; (c) Y. Hong, J. W. Y. Lam and B. Z. Tang, Chem. Commun., 2009, 4332; (d) Y. Hong, J. W. Y. Lam and B. Z. Tang, Chem. Soc. Rev., 2011, 40, 5361; (e) D. Ding, K. Li, B. Liu and B. Z. Tang, Acc. Chem. Res., 2013, 46, 2441; (f) S. J. Yoon, J. H. Kim, K. S. Kim, J. W. Chung, B. Heinrich, F. Mathevet, P. Kim, B. Donnio, A. J. Attias, D. Kim and S. Y. Park, Adv. Funct. Mater., 2012, 22, 61; $(g)$ N. B. Shustova, A. F. Cozzolino, S. Reineke, M. Baldo and M. Dincă, J. Am. Chem. Soc., 2013, 135, 13326; (h) J. Huang, X. Yang, J. Wang, C. Zhong, L. Wang, J. Qin and Z. Li, J. Mater. Chem., 2012, 22, 2478.

2 W. Qin, D. Ding, J. Z. Liu, W. Z. Yuan, Y. Hu, B. Liu and B. Z. Tang, Adv. Funct. Mater., 2012, 22, 771.

3 (a) K. Li, Y. H. Jiang, D. Ding, X. Zhang, Y. T. Liu, J. L. Hua, S. S. Feng and B. Liu, Chem. Commun., 2011, 47, 7323; (b) D. Ding, K. Li, W. Qin, R. Y. Zhan, Y. Hu, J. Z. Liu, B. Z. Tang and B. Liu, Adv. Healthcare Mater., 2013, 2, 500.

4 H. Tong, Y. Hong, Y. Q. Dong, M. Haussler, J. W. Y. Lam, Z. Li, Z. F. Guo, Z. H. Guo and B. Z. Tang, Chem. Commun., 2006, 3705.

5 Y. Hong, M. Haussler, J. W. Y. Lam, Z. Li, K. K. Sin, Y. Q. Dong, H. Tong, J. Z. Liu, A. J. Qin, R. Renneberg and B. Z. Tang, Chem.-Eur. J., 2008, 14, 6428.

6 H. Tong, Y. Hong, Y. Q. Dong, M. Haeussler, Z. Li, J. W. Y. Lam, Y. P. Dong, H. H. Y. Sung, I. D. Williams and B. Z. Tang, J. Phys. Chem. B, 2007, 111, 11817.

7 (a) N. A. Platé, T. L. Lebedeva and L. I. Valuev, Polym. J., 1999, 31, 21; (b) H. Y. Liu and X. X. Zhu, Polymer, 1999, 40, 6985; (c) Y. Chen, J. E. Gautrot and X. X. Zhu, Langmuir, 2007, 23, 1047.

8 K. Iwai, Y. Matsumura, S. Uchiyama and A. P. Silva, J. Mater. Chem., 2005, 15, 2796.

9 L. Tang, J. K. Jin, A. Qin, W. Z. Yuan, Y. Mao, J. Mei, J. Z. Sun and B. Z. Tang, Chem. Commun., 2009, 4974.

10 (a) C. Y. Gong, S. Shi, P. W. Dong, B. Kan, M. L. Gou, X. H. Wang, X. Y. Li, F. Luo, X. Zhao, Y. Q. Wei and Z. Y. Qian, Int. J. Pharm., 2009, 365, 89; (b) X. Yin, F. Meng and L. Wang, J. Mater. Chem. C, 2013, 1, 6767.

11 (a) A. J. Dong, Y. L. Zhai, L. Xiao, H. Y. Qi, Q. Tian, L. D. Deng and R. W. Guo, J. Polym. Sci., Part A: Polym. Chem., 2010, 48, 503; (b) L. N. Goswami, Z. H. Houston, S. J. Sarma, S. S. Jalisatgi and M. F. Hawthorne, Org. Biomol. Chem., 2013, 11, 1116.

12 A. C. Albertsson and I. K. Varma, Biomacromolecules, 2003, 4, 146.

13 F. Couet, N. Rajan and D. Mantovani, Macromol. Biosci., 2007, 7, 701.

14 R. R. Hu, J. W. Y. Lam, J. Z. Liu, H. H. Y. Sung, I. D. Williams, Z. N. Yue, K. S. Wong, M. M. F. Yuen and B. Z. Tang, Polym. Chem., 2012, 3, 1481. 